\title{
Orthodontic movement of endodontically treated teeth
}

\author{
Alberto Consolaro1, Renata Bianco Consolaro²
}

Often there is the need of moving teeth endodontically treated or teeth still in endodontic treatment. In order to collaborate with the comprehension and substantiation of the following subjects will be discussed: 1) Orthodontic movement in endodontically treated teeth without periapical lesion, 2) Orthodontic movement in endodontically treated teeth with inflammatory periapical lesion, and 3) Orthodontic movement in teeth endodontically treated due to aseptic pulp necrosis by dental trauma. In practically all situations, endodontically treated teeth to be orthodontically moved must be subjected to a careful evaluation by the endodontist about the conditions, adequate or not, of the endodontic treatment. Then, in this paper it was sought to induce an insight for new clinical researches about the theme that may definitely prove the information obtained by interrelations of information in parallel to clinical practice.

Keywords: Orthodontics-endodontics. Endodontic treatment-orthodontics. Periapical diseases-orthodontics. Orthodontics-dental trauma.

Com frequência, há a necessidade de movimentar-se dentes endodonticamente tratados ou ainda em tratamento endodôntico. Para colaborar com a compreensão e fundamentação do assunto, abordaremos: 1) a movimentação ortodôntica em dentes endodonticamente tratados sem lesão periapical; 2) a movimentação ortodôntica em dentes endodonticamente tratados com lesão periapical inflamatória; e 3) a movimentação ortodôntica em dentes endodonticamente tratados de necrose pulpar asséptica por traumatismo dentário. Em praticamente todas as situações, dentes endodonticamente tratados a serem movimentados ortodonticamente devem ser submetidos a uma avaliação criteriosa, por parte do endodontista, sobre as condições adequadas ou não do tratamento endodôntico. Em seguida, no presente trabalho procurou-se, singelamente, induzir um insight para novas pesquisas clínicas sobre o tema, que possam definitivamente comprovar os conhecimentos obtidos pela inter-relação de conhecimentos em paralelo à prática clínica.

Palavras-chave: Ortodontia-Endodontia. Tratamento endodôntico-Ortodontia. Periapicopatias-Ortodontia. Ortodontia-traumatismo dentário.

It is frequent the need of moving endodontically treated teeth or teeth still in endodontic treatment. What underlies the clinical decisions and biological orientations routinely applied is based on the interrelation of information pertinent to inflammation, tissue repair, tooth movement biology and of associated resorptions, pulp diseases and periapical disease. To collaborate with the comprehension and substantiation of this subject, it will be discussed together with these interrelations and experiences obtained over time. It was also sought to induce in this insight new clinical researches about the theme.

\footnotetext{
${ }^{1}$ Head Professor, FOB-USP. Professor of the Post-Graduation Course, FORP-USP.

${ }^{2}$ Professor, Adamantinenses Integrated Schools (FAI). PhD in Pathology, FOB-USP.

" The authors report no commercial, proprietary or financial interest in the products or companies described in this article.
}

\section{ORTHODONTIC MOVEMENT IN ENDODONTICALLY TREATED TEETH WITHOUT PERIAPICAL LESION}

During many decades, until 1990, there was practically no movement of teeth that were endodontically treated. There was almost a consensus, not methodologically substantiated, that these teeth would present greater risk of root resorption during orthodontic movement.

From the 90s on, after the publication by Spurrier et $\mathrm{al},{ }^{4}$ it was emphasized that teeth properly endodontically treated, if orthodontically moved, would not increase the risk of root resorption, nor reduce this risk.

How to cite this article: Consolaro A, Consolaro RB. Orthodontic movement of endodontically treated teeth. Dental Press J Orthod. 2013 July-Aug;18(4):2-7.

Submitted: June 18, 2013

Revised and accepted: July 10, 2013

Contact address: Alberto Consolaro

E-mail: consolaro@uol.com.br 
In the current context of Dentistry, there are more and more healthy teeth, and the required endodontic treatment comes from needs related to dental trauma. However, there is still many teeth endodontically treated because of dental cavity, specially clinical cases in which the necessity or not of endodontic retreatments is questioned. The improvement in economic and social conditions leads many adults to undergo orthodontic treatments and among older adults previously performed endodontically treatments are still very common.

There was marked reduction of endodontic treatment due to caries, which was gradually substituted by those due to dental trauma, considering the several ways and the greater opportunity to leisure and sports, and to the greater mobility by the several transportation means to which men submit with greater chances of accidents, especially in the large cities.

Orthodontic movement is done due to the periodontal ligament. ${ }^{2}$ Cementoblasts have no receptors for bone turnover mediators, but the osteoblasts located $0.25 \mathrm{~mm}$ from the tooth have them. The application of an orthodontic force:

1. Compresses the cells, deforming its cytoskeleton, promoting a mechanical stress.

2. And, at the same time, reduces the lumens of blood vessels with hypoxia in the area establishing a metabolic stress.

The stressed cells of the periodontal ligament release many mediators that alternately stimulate the resorption and the bone position on the ligament surface of the alveolar process, promoting local bone remodeling, fixating the tooth in a new position. The root resorption induced during orthodontic treatment will only occur if the applied forces also cause the death of cementoblasts with subsequent exposition of the root surface. The death of cementoblasts is necessarily associated to more intense forces that compress the vessels in certain areas of the periodontal ligament.

The pulp tissues, on the other hand, do not suffer morphological and functional alterations during orthodontic movement, ${ }^{1,3}$ regardless of the type and intensity of the applied force. Thus, in the same way, if the canal is filled by endodontic material, it will also not cause any modification on the periodontal tissues before orthodontic movement. In other words, if a tooth properly endodontically treated is orthodontically moved and presents less or more root resorptions, this response is not directly related to the present orthodontic treatment.

In practically all situations, endodontically treated teeth to be orthodontically moved must be subjected to a careful evaluation about the adequate conditions or not of the endodontic treatment by the endodontist. In cases in which these conditions are considered inadequate or inappropriate an endodontic retreatment must be performed.

\section{Possible consequences}

Reactivation of previous periapical lesions - the apical resorptions due to applied forces, a common and acceptable event from the clinical point of view - may "open" canaliculi, tubules and accessory canals of apical deltas that still had bacterial components. These products may, temporarily, promote the relapse of chronic periapical lesions such as chronic apical pericementitis and/or periapical granuloma.

The local microbiota in these conditions have its pathogenic limits since there is no nutritional source for an exuberant microbial proliferation due to the lack of communication with the oral environment. When ceasing orthodontic treatment, the process tends to regress; if the regression doesn't happen, the tooth must be endodontically retreated. This situation is quite rare, but theoretically can occur in sporadic cases.

Pseudo-overfilling - apical resorptions due to applied forces round and shorten the tooth, but the guttapercha cones and some sealers are not phagocytable by the macrophages and/or by the clasts. After orthodontic treatment, the appearance will be of a gutta-percha cone surpassing the most apical limit of the tooth. ${ }^{2}$ This situation is relatively common.

\section{How long to wait and explanations}

If the orthodontic movement does not change the pulp biology from the morphologic point of view, nor age it, the endodontic treatment, in the same way, does not interfere on the cellular and tissue phenomena of tooth movement. Strictly speaking, from the biological point of view and correlating the information about pulp biology and orthodontic movement, the application of forces can be done after a few days of the conclusion of endodontic treatment. Between 15 and 30 days, the exudate (liquids) and the inflammatory infiltrate (cells) were absorbed and migrated from the site. 
In cases of orthodontic movement of endodontically treated teeth in which a failure of months or years was detected, this fact must not be assigned to the performed tooth movement. The applied forces do not interfere on the pathogenicity and on the virulence of the associated microbiota, as well as in the biology of microbial biofilms and chronic inflammatory periapical lesions. The failure must be justified from the limitations inherent to the endodontic treatment.

\section{ORTHODONTIC MOVEMENT IN ENDODON- TICALLY TREATED TEETH WITH INFLAMMA- TORY PERIAPICAL LESION}

The periapical lesions are exclusive of the periapex; eventually, some other lesions may be locate in this region and not be considered true periapical diseases. The periapical diseases are the most common maxillary intrabony lesions.

The periapical lesions or periapical diseases are predominantly inflammatory and associated to the microbiota present in the canals in which the dental pulp is necrotic, or yet associated to pulp aseptic necrosis due to dental trauma.

The non-inflammatory periapical diseases are, relatively, much less frequent and can be:

1) Cemental dysplasia or periapical cemento-osseous dysplasia: An osteofibrous dysplasia of the periapical bone of lower incisors;

2) Benign cementoblastoma: An odontogenic neoplasia, almost exclusive of the periapex of lower first molars.

Among the non-inflammatory periapical diseases, the periapical cemento-osseous dysplasia requires secure diagnosis and only monitoring, without any treatment and consequence for the patient; the benign cementoblastoma must be surgically removed with a good prognosis.

The inflammatory periapical diseases may be associated to two basic conditions: pulp necrosis associated to a rich and mixed microbiota and to pulp aseptic necrosis due to trauma.

Every inflammatory periapical lesion begins as acute apical pericementitis which may evolve to:

1) Acute dentoalveolar abscess, and then chronic, characterized by the fistula.

2) Chronic apical pericementitis and then periapical granuloma which may remain for months or years, or yet, evolve eventually to apical periodontal cyst.
In the case of the acute inflammatory periapical diseases - acute pericementitis and dentoalveolar abscess in its several phases - endodontic treatment has an excellent prognosis if considering that there is no time or local conditions to occur significant and minimum areas of apical resorption. The bacteria will have a shorter period and more regular root surface, which complicates its permanence in the root structure after the adequate endodontic treatment.

On the chronic inflammatory periapical diseases - chronic apical pericementitis and periapical granuloma - the permanence period of the microbiota is much longer than in the acute, allowing bacteria to colonize the dental tubules and the irregular areas of apical absorption. At the same time, many bacteria colonize the external part of the apical surface forming microbial biofilms. These conditions allow a good prognosis, but with reservation, because the endodontic technique, even being evolved, still does not guarantee complete elimination of this microbial component. There is still a percentage rate to be considered on failures in cases of endodontic treatment of teeth with chronic periapical lesion, around 10 and 35\%, according to analyzed cases.

The periapical granuloma consists of an agglomerate somewhat organized of inflammatory cells, specially macrophages, lymphocytes and plasma cells. These cells are nourished by numerous vessels and physically supported by the exudate and by an extracellular matrix with fibroblasts and eventual collagen fibers. Dimensionally and by analogy, the periapical granuloma can be compared to a pillow of soft tissue accommodated and wrapping the most apical part of the tooth root.

When referring to chronic inflammatory periapical disease it is often related to the periapical granuloma, because in apical periodontal cysts still small and located on the context of a periapical granuloma, the endodontic treatment is also efficient.

What keeps the periapical granuloma active is the constant leave of bacterial products and of the bacteria itself to the periapical region, especially in the cemental canal. The elimination of the microbial source by an adequate endodontic treatment implies in eliminating the stimulus. Immediately after the endodontic treatment, the macrophages and other cells from the periapical granuloma eliminate the last bacteria and its products and, in hours, eliminate them. 
They also did that before, but the leave of bacteria was constant. In a few hours or a couple of days, the periapical granuloma gives way to a tissue free of bacteria and its products thanks to the macrophage activity. The space of the periapical granuloma becomes occupied by a granulation tissue rich in vessels and with osteoblast cells invading it for the bone repair to occur.

The repair initiates in hours, as soon as the microbial agents are eliminated. However, the local bone repair will take long to generate a radiographic image of a normal periapical bone. The generation of these images depends on a higher degree of tissue maturity and mineral density that might take weeks and even months to be achieved.

\section{Possible consequences}

Besides the pseudo-overfilling by the end of the orthodontic treatment, other consequences are independent from the orthodontic movement, such as the persistence of the lesion or its partial regression, or even its increase. In these cases, the endodontic treatment must be evaluated regarding its capacity of completely eliminating the microbiota, closing the spaces occupied by it and the possibility of the involved tooth having a different morphology that would complicate the elimination of the microbiota by the endodontic treatment, such as apical delta, dilacerations, developmental groove and others. To assign the failure to the fact that the tooth was orthodontically moved is not pertinent.

\section{How long to wait and explanations}

It must be emphasized that the forces applied in a certain tissue do not modify or potentiate the action of settled microbiotas. The application of orthodontic forces in chronic periapical lesions of teeth properly endodontically treated would not interfere on the microbiota nor on the repair.

The first thought would be: But wouldn't the forces compress the vessels of the region in repair and complicate cellular proliferation and the synthesis of new tissue components? No, because the apical and periapical region is filled by soft tissue from the old periapical granuloma or from the granulation tissue of the ongoing repair. The application of forces in this area cannot compress the vessels, the walls are not hard and limited by a periodontal space of $0.25 \mathrm{~mm}$.
In fact, there is a large area of soft tissue in reconstruction. The force necessary to compress a fragile structure such as the periodontal ligament will not have effect on a soft tissue in a wider area, like where the repair is in an area previously occupied by a chronic periapical lesion.

Strictly speaking, from the biological point of view, by what is known and conceived as orthodontic force, there wouldn't be a way for it to interfere on the repair of chronic periapical lesions after an adequate orthodontic treatment. Again, the movement of a tooth with chronic periapical lesion endodontically treated can be done after a few days. A period between 15 and 30 days would be more than enough for the exudate and inflammatory infiltrate to be respectively absorbed and migrate from the area, remaining only the macrophages and other cells that were participating of the granulation tissue in the repair of the area.

In cases of orthodontic movement of endodontically treated teeth in which a failure over months or years was detected, this fact must not be assigned to the performed tooth movement. The applied forces do not interfere on the pathogenicity and on the virulence of the associated microbiota, as well as on the biology of microbial biofilms and chronic inflammatory periapical lesions.

The failure in these cases must be justified by the limitations inherent to the endodontic treatment and not by the fact that the tooth was subjected to orthodontic movement. In teeth with chronic periapical lesions the frequency of irregular areas due to apical resorptions associated to it is very high, increasing the possibility of persistence of microbial biofilms. The occurrence of failures on the hermetic closure of the apical opening due to natural anatomical irregularities can also justify these failures, as well as the presence of apical deltas, the used material and many other factors that affect the final results. The possibility of failure in endodontically treated teeth with chronic periapical lesion is greater than in other situations.

\section{ORTHODONTIC MOVEMENT IN ENDODON- TICALLY TREATED TEETH FROM ASEPTIC PULP NECROSIS BY DENTAL TRAUMA}

The aseptic pulp necrosis can be treated right after its occurrence, but it can also be clinically ignored and, only months or years later, be detected - by coronary darken- 
ing or in routine radiographic exams, as those performed for orthodontic planning. When diagnosed too much later, the aseptic necrosis may present chronic apical pericementitis and/or even a small periapical granuloma.

After one year, half of the aseptic pulp necrosis tend to present microbiota, by hematogenous retrograde invasion of the root canal. In general, it represents a microbiota of low aggressiveness and with low metabolic activity, since the involved teeth did not present periodontal involvement or dentin and pulp exposure to the oral environment.

With or without periapical lesion, endodontically treated teeth for aseptic pulp necrosis due to dental trauma, if orthodontically moved could have the same behavior expected from those teeth endodontically treated for pulp necrosis with infected canals. However, this situation must be faced in a different way by the following rule: Every tooth previously traumatized, if moved, may present earlier and more intense root resorptions by the end of the orthodontic treatment.

This rule is regardless if the tooth was endodontically treated by aseptic necrosis or not. In dental trauma there is a greater chance of repair of the cementoblastic layer be, focally and in eventual spots, done with cells of osteoblastic lineage that have receptors for bone turnover mediators. In dental trauma the lesions of the cementoblastic layers are more extensive than the ones induced on orthodontic treatment.

Despite behaving - morphological and physiologically - like cementoblast or cementoblast-like cells, with the usual mediator accumulation on the ligament, by the compression of orthodontic forces, it is led to periodontal bone resorption as expected; but now also to root resorption which in normal conditions is protected by the true cementoblast cells without receptors for such mediators. This is because the cementoblast-like cells, true osteoblasts, soon take on the management of the bone remodeling units after a few hours of force application, resorbing the root.

The previously traumatized teeth, with or without aseptic pulp necrosis and endodontic treatment properly performed, can be orthodontically moved, but the professional must scale the forces, evenly distributing them as much as possible on the dental structure and perform periapical radiographic control every three months to verify the degree of root re- sorption, if happening. Within possibility, these teeth must be avoided as point of anchorage or subjected to extensive movements and intrusive mechanics; if there is no other option, they can be subjected, but will present a higher degree of root resorption.

\section{Possible consequences}

The inconvenient consequences of orthodontic movement of teeth endodontically treated from aseptic pulp necrosis due to dental trauma are related, mainly, to the fact that the tooth was previously traumatized: the root resorptions may be greater by the end of the orthodontic treatment. As for being an endodontically treated tooth, there would be no contraindication especially because it refers to teeth with aseptic pulp necrosis that, when retrograde and secondarily contaminated via blood, the microbiota has low virulence.

\section{How long to wait and explanations}

Every tooth previously traumatized, if moved, may present earlier and more intense root resorptions by the end of the orthodontic treatment. This possibility justifies the rule of waiting a period of time for this type of tooth to be subjected to orthodontic movement which is almost universally accepted and followed. ${ }^{2}$ The period varies with the classification of the trauma in mild, moderate and severe.

In mild trauma, as concussion and discrete subluxation, it must wait 3 to 4 months to provide a new periapical radiograph or tomograph and evaluate if the periodontal tissues and structures went back to normal. If so, the traumatized tooth can be moved.

Moderate dental trauma characterized by more severe subluxation, luxation, displacement and even extrusion without total avulsion of the tooth on the alveolus, must wait one year. If new periapical radiographs and/or tomographs after this period reveal structural and organizational normality, absence of dental alveolar ankylosis, resorption by substitution and/or inflammatory resorption, the tooth can be orthodontically moved.

In more severe cases, as total avulsion followed by reimplantation until 30 to 60 minutes out of the alveolus and in cases of root fracture, it must wait 2 years. After this period, if new periapical radiographs and/or tomographs reveal structural and 
organizational normality, without dental alveolar ankylosis, without resorption by substitution and or without inflammatory resorption, the tooth can be orthodontically moved. Always considering the rule that they may present greater root resorption by the end of the orthodontic treatment.

\section{FINAL CONSIDERATIONS: THE "INSIGHT"}

The statements of the previous topics are based on the interrelation of information pertinent to inflammation, tissue repair, biology of the dental movement and of the associated resorptions, pulp and periapical diseases. There is still no work in the literature in which significant number of cases of endodontically treated teeth have been moved in the context of orthodontic treatment. There is a lack of methodologically adequate and comparative studies where there were:

1) A group of endodontically treated teeth for pulp necrosis with infected canals, without chronic periapical lesion and, then, orthodontically moved; with the final result evaluated by the end of treatment, regarding the severity of the associated resorption, when it happen and/or other consequences such as pseudo-overfilling, reactivation of previous lesions, endodontic failure index and other phenomena.
2) Another group of teeth endodontically treated for pulp necrosis with infected canal, with chronic periapical lesion and, then, orthodontically moved; with the final result evaluated by the end of treatment, regarding the severity of the associated resorption, when it happened and/or other consequences such as pseudo-overfilling, increase or partial/total regression of the previous lesions, endodontic failure index and other phenomena.

3) A third group of teeth endodontically treated from aseptic pulp necrosis induced by dental trauma and, then, orthodontically moved; with the final result evaluated by the end of treatment regarding the severity of the associated resorption when it happened and/or other consequences such as pseudooverfilling, reactivation of previous lesions, endodontic failure index and other phenomena.

4) The fourth group of patients with teeth with pulp vitality and moved similarly to the other three groups, a control group. A special care on the performance of these researches is regarding the maximum standardization possible of the orthodontic treatment performed in each patient in all four groups, especially regarding the type and extension of the movement, intensity and distribution of applied forces. In the same way, the period in which the endodontic treatment was initiated should be standardized.
REFERENCES

1. Consolaro A. Alterações pulpares induzidas pelo tratamento ortodôntico: dogmas e falta de informações. Rev Dental Press Ortod Ortop Facial. 2007:12(1):15-7.

2. Consolaro A. Reabsorções dentárias nas especialidades clínicas. 3a ed. Maringá: Dental Press; 2012

3. Consolaro RB. Análise do complexo dentinopulpar em dentes submetidos à movimentação dentária induzida em ratos [dissertação] Bauru (SP): Universidade de São Paulo; 2005.

4. Spurrier SW, Hall SH, Joondeph DR, Shapiro PA, Riedel RA. A comparison of apical root resorption during orthodontic treatment in endodontically treated and vital teeth. Am J Orthod Dentofacial Orthop. 1990;97(2):130-4 